\title{
THE EXTENDED INTEGRATED MODEL OF KANSEI ENGINEERING, KANO, AND TRIZ INCORPORATING CULTURAL DIFFERENCES INTO SERVICES
}

\author{
Markus Hartono ${ }^{1 *}$ \\ ${ }^{1}$ Department of Industrial Engineering, Faculty of Engineering, University of Surabaya, Jalan Raya \\ Kalirungkut, Tenggilis, Surabaya 60293, Indonesia
}

(Received: September 2015 / Revised: September 2015 / Accepted: January 2016)

\begin{abstract}
The fulfilment of customers' emotional needs (Kansei in Japanese) tends to be highly expected, especially in growing industries such as the service industry. Recent research shows that emotion is just as important as cognition in service-related encounters. Thus, service providers should not overlook the significant roles of both emotional and cognitive aspects in achieving service excellence for customers. In modeling how to capture and translate customers' emotional needs into services, Kansei Engineering (KE) is used. This study aims to integrate Kansei Engineering with the Kano model and the Theory of Inventive Problem Solving (TRIZ). The Kano model is used to identify the relationship between service attribute performance and customer satisfaction, whereas TRIZ is utilized subsequently to generate designs for improvement with the lowest contradiction between the proposed service design solutions. Due to relatively unexplored cultural differences in Kansei research, cultural factors are also considered and incorporated into the integrated model. It is hoped that further insight into the emotional needs of customers from different cultural backgrounds will be better understood, so that the improvement strategies will be suitable. In addition, to illustrate the applicability of the integrated model, an empirical study in a medium-sized restaurant that takes into account both Indonesian and non-Indonesian customers will be discussed.
\end{abstract}

Keywords: Cultural differences; Customer service; Kano; Kansei Engineering; TRIZ

\section{INTRODUCTION}

Quality is not only for products, but also for services (Nagamachi \& Lokman, 2011; Hartono \& Tan, 2011). Positive customer perceptions impact both cognitive and emotional satisfaction, known as total customer satisfaction. For understanding customers' emotional needs in product/service design and development, Kansei Engineering has been intensively used (Nagamachi, 1995; Hartono et al., 2013) as a quality management system that grasps the customer's emotions and improves the quality level to always satisfy them. The application of Kansei Engineering in the service industry is relatively new. The challenge for service providers is to deliver a consistent Kansei all the way through all main processes, ranging from pre-purchase to post-purchase activities.

Similar to a previous study by Hartono and Tan (2011), the current study also applies the SERVQUAL model as the service attributes, regarded as the stimuli for customers' Kansei. It is deployed in five different dimensions: tangibility, reliability, responsiveness, empathy, and assurance (Parasuraman et al., 1988). Although all service attributes are important,

\footnotetext{
*Corresponding author's email: markus@staff.ubaya.ac.id, Tel. +62-31-2981392, Fax.+62-31-2981376 Permalink/DOI: http://dx.doi.org/10.14716/ijtech.v7i1.1789
} 